Accountants in association with the University of Lancaster, Mr. R. W. V. Dickerson recommends that the training of the financial administrator should be entrusted mainly to the universities or to regional colleges engaged in research as well as in teaching. While Mr. Dickerson urges the Institute to extend its functions to include training, he considers that the universities and colleges are the only institutions which can hope to discover what the new accountancy should be, how it should be taught and how it should be adapted to changing needs and circumstances. It should surely no longer be necessary to argue either the importance of management studies or their appropriateness as a subject of university study: the question is now rather that of how they should be organized and on what scale. Throughout Mr. Platt's address it is implicit that the universities themselves are likely to be immensely benefited by such studies, if only hecause they are challenged once again to consider the purpose of a university education, and what is involved to-day, even if it were accepted as no more than that of fitting its students adequately to fill responsible professional positions.

\section{A NEW APPRAISAL OF RADIATION GENETICS}

\section{Problems of Radiation Genetics}

By N. P. Dubinin. Translated by G. H. Beale. Pp. ix +445 . (Edinburgh and London: Oliver and Boyd, Ltd., 1964.) $110 s$.

I

$\mathrm{N}$ the forty years of its existence, radiation genetics has developed into a vast field with many interrelated, specialist areas devoted to physical, chemical, genetical and cytological analysis of the action of ionizing and nonionizing radiation on biological material. As a tool for dissecting the genetic material and its function, radiation genetics has remained unrivalled for many years; even now, it is in many ways superior to chemical mutagens in this respect. To the purely theoretical interest of radiation genetics, the past few decades have added practical considerations of major importance. On the negative side, steps have to be taken to minimize the genetical dangers of radiation; on the positive side, 'mutation breeding' has already proved its value for the improvement of microorganisms and agricultural plants. Ten years ago, all available knowledge on the subject was summarized in the four volumes of the Handbook of Radiation Biology ${ }^{1}$. Since then, the discovery of the chemical nature of the gene and its functions has led to a revolution in our interpretation of radiation data, and although much of the Handbook remains of abiding value, a new appraisal of the whole field was urgently desirable.

Such a new appraisal is provided in Dr. Dubinin's Problems of Radiation Genetics. Although it is already behindhand by several years in this rapidly expanding field, it is yet firmly based on our new ideas of molecular biology. It should, therefore, not be too difficult to bring the facts up to date in a new edition. After an introductory chapter on the fundamentals of genetics and cytology and a second chapter--by S. L. Shirokov-on the physical principles involved, the book deals with the genetical and cytological effects of ionizing radiation, ultra-violet light and visible light (photodynamic action). Special chapters are devoted to the radiation genetics of mammals, the dangers of ionizing radiation for mankind, and radiation breeding of plants and micro-organisms. The individual chapters-apart from the two introductory ones-are review articles rather than analytical discussions. A reader who looks in them for the type of profound and sophisticated analysis to which Muller in his Handbook articles subjected the then available evidence will be disappointed. There is a certain amount of weighing of evidence, and the scientific standing of the author guarantees that no truly untrustworthy or disproved evidence will have been included without criticism; but by and large it is left to the reader to sift the evidence and draw his conclusions. What the book has lost in depth by this manner of treatment, it has gained in breadth. An enormous amount of information is presented. The list of references comprises nearly 900 titles, about 180 from Russian authors. A curious omission is that of the fundamental paper by Raffel and Muller on "Gene Divisibility", a problem discussed fully in the first chapter. Unfortunately, no references are given to the origin of text figures, many of which are graphic representations of data which the reader may wish to study in the original; this should be amended in a future edition.

In spite of the vast amount of material covered, the writing is discursive and, to some extent, repetitive. This way of presentation makes for easier reading and helps to drive home important findings from different angles, but it makes it difficult for the reader to find the places in the book which deal with any special problem. It is, for example, not easy to guess that radiation-induced cancer occupies several pages of the section called "New problems in human and mammalian radiation genetics", or that the effects of irradiated medium are discussed in two places, separated by 12 pages. The two brief indexes, provided by the translator, are of some help, but a much more detailed index is needed for making the best use of the book. Headings of sub-sections would be an additional aid.

In a number of respects, one feels that the book was written when Russian genetics was still under suspicion of being 'idealistic', useless and subversive. The Western reader will be bewildered by the reasoning that culminates in the conclusion that "the discovery of the purely material nature of the complex processes of life" is "one of the major landmarks in the history of dialectical materialism". There is also a distinct flavour of apologetics in the recurrent emphasis on the practical importance of radiation genetics, far beyond what can reasonably be expected from it. Thus, deciphering the DNA code is said to be potentially useful as a model of a code for technological purposes, such as the programming of Sputniks and spaceships. The possibility of mutation breeding is fantastically overrated in the statement that "when he is able to change deliberately the arrangements of atoms in the molecule of genetic material, man will be able to create new desired forms of plants, animals, micro-organisms and viruses". One hopes that in future editions such pandering to political prejudices will no longer be necessary.

The translation is excellent and gives the reader the reassuring feeling of its having been done by an expert geneticist who has himself checked not only the references (excluding some Russian ones) but also whatever might have seemed obscure or ambiguous in literal translation. Charlotte Auerbach ${ }^{1}$ Radiation Biology, edit. by Hollsender, A. (McGraw-Hill Book Co., Inc.,
New York, $1954-1956$.

\section{BIOLOGICAL EFFECTS OF NEUTRON AND PROTON IRRADIATORS}

Biological Effects of Neutron and Proton Irradiations (Proceedings of the Symposium held by the International Atomic Agency at the Brookhaven National Laboratory, Upton, New York, 7-11 October, 1963.) Vol. I: Pp. 433. Vol. 2: Pp. 446. (Vienna: International Atomic Energy Agency; London: H.M.S.O., 1964.) 189 schillings; 54s.; 9 dollars each volume.

D EADING these Proceedings, one can only conclude R that this must have been a most exciting meeting. Volume 1 begins with the two sessions devoted to dosi- 